\title{
Performance evaluation of a tractor mounted groundnut pod collecting machine
}

\section{Saumya Shukla, Priyanka R. Khole and R. A. Gupta}

Received : 10.01.2018; Revised : 02.03.2018; Accepted : 14.03.2018

See end of the Paper for authors' affiliation

Correspondence to :

Saumya Shukla

Department of Farm Machinery and Power,

Junagadh Agricultural

University, Junagadh

(Gujarat) India

Email : saumyashuklalk@

gmail.com
-ABSTRACT : The performance of a tractor mounted groundnut pod collector was evaluated at different levels of machine speed (1.0-1.5, 1.5-2.0 and 2.0-2.5 km/h) and sieve oscillations (200, 250 and $300 \mathrm{rpm}$ ) at a constant penetration depth of $10 \mathrm{~cm}$. The performance of the machine was found to be better at $1.5-2.0 \mathrm{~km} / \mathrm{h}$ forward speed and $250 \mathrm{rpm}$ sieve oscillations, respectively, looking to minimum losses and maximum pod collection efficiency. Pod collection efficiency was found maximum $(93.75 \%)$ at $1.5-2.0 \mathrm{~km} / \mathrm{h}$ and $250 \mathrm{rpm}$. The theoretical field capacity of groundnut pod collector was found as $0.22 \mathrm{ha} / \mathrm{h}$ while effective field capacity was $0.18 \mathrm{ha} / \mathrm{h}$ and field efficiency was 81.81 per cent. On comparison with manual pod collection method, there was 88.42 per cent reduction in time while 48.10 per cent reduction in pod collection cost was observed.

- KEY WORDS : Performance, Groundnuts, Tractor mounted, Pod collection, Cost economics

- HOW TO CITE THIS PAPER : Shukla, Saumya, Khole, Priyanka R. and Gupta, R.A.(2018). Performance evaluation of a tractor mounted groundnut pod collecting machine. Internat. J. Agric. Engg., 11(1) : 190-198, DOI: 10.15740/HAS/IJAE/11.1/190-198. 